\title{
Erysipelatoid Carcinoma
}

\author{
Thiago Sande Miguel ${ }^{\mathbf{1}}$ \\ Daniel Almeida da Costa ${ }^{1}$ \\ Ana Paula Moura de Almeida ${ }^{2}$ \\ Livia Cristina de Melo Pino ${ }^{1}$ \\ D Daniel Cohen Goldemberg ${ }^{3}$ \\ Bruna Sande Miguel ${ }^{4}$ \\ Sebastiao Célio Horta Coelho Filho ${ }^{1}$ \\ 1. Medical School of Valença - Rio de Janeiro, RJ, Brasil \\ 2. Medical School of de Campos, Campos, RJ, Brasil \\ 3. National Cancer Institute of Brasil - INCA, Rio de laneiro, RI, Brasil \\ 4. UNIGRANRIO University, Rio de Janeiro, RJ, Brasil
}

\section{SUMMARY}

Erysipelatoid Carcinoma (EC), also known as Inflammatory Metastatic Carcinoma, is a rare form of cutaneous metastasis, secondary to an internal malignancy, more often related to breast cancer. Clinically, the lesion has a well-marked, bound erythematous appearance, much like an infectious process, such as erysipelas and cellulitis, these being the most common differential diagnoses. It is characterized by an acute or subacute appearance with an erythematous plaque, sometimes hot and painful, being more often situated in the primary tumor vicinity, especially in the thorax wall in the region of a mastectomy due to breast cancer. Here we present the case of a 75-year-old patient with ductal infiltrated carcinoma for 3 years, who presented an acute erythematous and infiltrated plaque in the region of a previous mastectomy, with a final diagnosis of $E C$.

KEYWORDS: Breast neoplasms. Erysipeloid. Skin neoplasms. Inflammation/pathology.

\section{INTRODUCTION}

Population aging due to increased life expectancy has led to a greater number of benign and malignant neoplasms cases and, consequently, their complications, including metastases. ${ }^{1,2}$ These can be defined as a dynamic process where the primary tumor cells migrate to different sites, through some mechanisms, including hematogenous, lymphatic dissemination, direct implantation from surgical procedures and adjacent tissue invasion by contiguity. ${ }^{3,4}$

Cutaneous metastasis from malignant neoplasia does not constitute a common event when compared to the frequency of liver and lung metastatic sites. However, because macroscopic aspects can be present, there is a greater chance that it is diagnosed in the initial stages. ${ }^{2-4}$

Cutaneous metastases usually occur concurrently with metastases in the lungs, liver and lymph nodes, but metastatic dissemination may be the first warning, or even the first sign, to indicate an underlying malignant neoplasm presence. ${ }^{4,5}$ In females, breast cancer was the most frequently associated with cutaneous metastasis, with up to $70 \%$ of total
DATE OF SUBMISSION: 17-Sep-2017

DATE OF ACCEPTANCE: 07-Jan-2018

CORRESPONDING AUTHOR: Daniel da Costa

R. Sargento Vitor Hugo, nำ161 | Fátima - Valença/R]

Rio de Janeiro - Brasil - 27600-000

E-mail: professordanielfmv@gmail.com thiagosande.miguel@hotmail.com medpaula@yahoo.com.br liviapino@gmail.com daniel.cohen@inca.gov.br brunasandemiguel@outlook.com sebastiaochcf@gmail.com professordanielfmv@gmail.com 
cases diagnosed with cutaneous metastasis. The dermatological clinical pattern of breast cancer metastasis is variable, predominantly metastases with a large number of non-painful papular-nodular, normochromic, or erythematous-violet clinical metastases, which are localized on the thoracic wall. ${ }^{6-9}$

Erisipelatoid Carcinoma (EC), also known as Inflammatory Metastatic Carcinoma, is a rare form of cutaneous metastasis secondary to internal malignancy. EC is an uncommon clinical finding, the incidence of cutaneous metastases to carcinomas varying from 0.7 to $10 \%{ }^{10-12}$ Lesions may present more nonspecific characteristics, such as subcutaneous or intra-dermal nodules, single or multiple, of generally stony consistency, rapid growth, adhered, of varying coloration, that sometimes ulcerate. However, in a more characteristic way of the pathology, they may manifest as papillary erythematous skin lesions, infiltrated and with edema presence, well-demarcated and slightly endured, that resemble much to an acute infectious process, such as erysipelas and cellulite, these being some of your most common diagnoses. ${ }^{13-16} \mathrm{EC}$ is more often secondary to breast cancer and less common in stomach cancers. ${ }^{1718}$ It is marked by an acute or subacute appearance, with an erythematous plaque, sometimes hot and painful, being situated near the primary tumor, especially in the thorax wall in a mastectomy due to breast cancer. ${ }^{19,20}$

EC is subdivided into primary and secondary forms. In the primary form, both, carcinoma and inflammatory changes occur simultaneously in a previously normal breast. Whereas in the secondary form, inflammatory changes occur later in a breast with previous carcinoma. ${ }^{9,12}$ EC spreads rapidly, both locally and systematically. The prognosis is adverse with less than 2.5 years of multimodality treatment. Axillary nodal involvement, younger age at diagnosis, African-American ethnicity and negative hormonal receptor status are some darker factors. .,6,21 $^{-1}$

Cutaneous metastasis denominate en cuirasse is the rarest cases, located exclusively on the chest wall and characterized by stiff, infiltrated sclerodermiform-like skin that attacks the scalp and is called neoplastic alopecia. ${ }^{22,23}$ Immunohistochemical techniques, such as cytokeratin 7 and cytokeratin 20, contribute to elucidate the diagnosis. BRST-2 antigen and estrogen and progesterone receptors may be useful for the diagnosis. ${ }^{3,5,9,15,16}$

EC treatment previously consisted only of surgery. However, this produced a less than 10\% 5-year survival rates. Mastectomy is currently preferred by conservative breast surgery, but only produces an overall survival of 12 to 32 months when used alone. Adjuvant radiotherapy has been shown to improve locoregional tumor control, but does not affect survival rates, so the multimodality therapy is now the preferred option. 12,19,21

Chemotherapy, neoadjuvant and/or postoperative, can improve overall survival rates when combined with local modalities, such as surgery and/or radiotherapy. ${ }^{10,12,13}$

This paper aims to present the clinical picture of an unusual pathology with details of its clinical and histopathological characteristics so that it is considered as one of the differential diagnoses of skin disorders.

\section{CASE REPORT}

We present a patient, NSG, 75 years old, female, white, natural and resident of Rio de Janeiro, Brazil. She contacted the dermatology service complaining of skin inflammation. Her present disease history was characterized by the presence of eyelid-like papule-erythematous, edematous, erythematous cutaneous plaques with precise, slightly indurated borders that resembled an acute infectious process, such as erysipelas and cellulitis, in a mastectomy region, 20 days before. She denied having had a fever and had already had previous treatment with cephalexin without improvement.

At the examination, infiltrated and hardened erythematous plaques of inaccurate limits were found, occupying the thorax and right breast anterolateral region. (figure 1 and 2 )

The previous pathological history consisted of ductal infiltrant carcinoma for 3 years in the right breast, treated with mastectomy and chemotherapy, Adriblastine and Genuxal, and radiotherapy.

Carcinoma Erysipelatoid, Angiosarcoma, and Erysipelas were then considered as diagnostic hypotheses.

To elucidate the case, complementary exams were conducted, such as a complete hemogram (Hemocytes: $4.12 / \mathrm{mm}^{3}$, hemoglobin $11.9 \mathrm{mg} / \mathrm{dl}$, hematocrit $36.5 \%$, and leukogram with 6400 leukocytes (0-3 / 0-0-2-65 / 24-12)), and biochemistry, which did not present alterations.

An incisional biopsy was performed, showing, in small and medium magnification, a skin fragment in- 


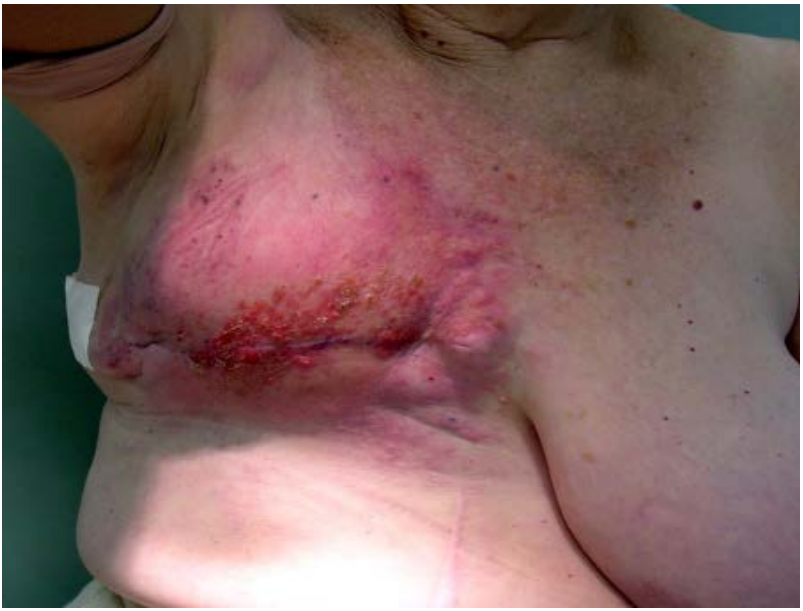

FIGURE 1. At the examination, infiltrated and hardened erythematous plaques of inaccurate limits were found, occupying the anterolateral region of the thorax and right breast.

filtrated by adenocarcinoma with atypical neoplastic cells forming cords and groups of tumor cells in the reticular dermis. (figures 3 and 4). There was also a considerable increase of irregular aggregates of atypical epithelial cells forming strands and groups of cells that vary in size and shape, infiltrated between reticular dermis collagen fibers. (figure 5)

Immunohistochemistry was performed, revealing positive cytokeratin 7 and BRST-2 antigen (GCDFP-15) and negative cytokeratin20 and estrogen receptor. (figure 6 and 7 )

In view of this, a diagnosis of Carcinoma Erisipelatoid diagnosis with mammary origin was established. After discussing the case with the oncology sector, chemotherapy was started with gemcitabine Hydrochloride and Paclitaxel. The patient presented partial edema and erythema regression after the 6th chemotherapy session.

It is noteworthy that the patient was previously and adequately informed about her pathological condition and its publication, consenting and signing the Free and Informed Consent Term.

\section{DISCUSSION}

EC is a rare form of cutaneous metastasis, secondary to internal malignancy and is commonly associated with breast carcinoma, especially with the intraductal carcinoma, presenting complications in $1-2 \%$ of malignant breast disease cases. ${ }^{13,14,24}$ The cutaneous malignant neoplasm metastasis of primary internal organs is rare, but when they occur, the most common primary site is the breast, in an av-

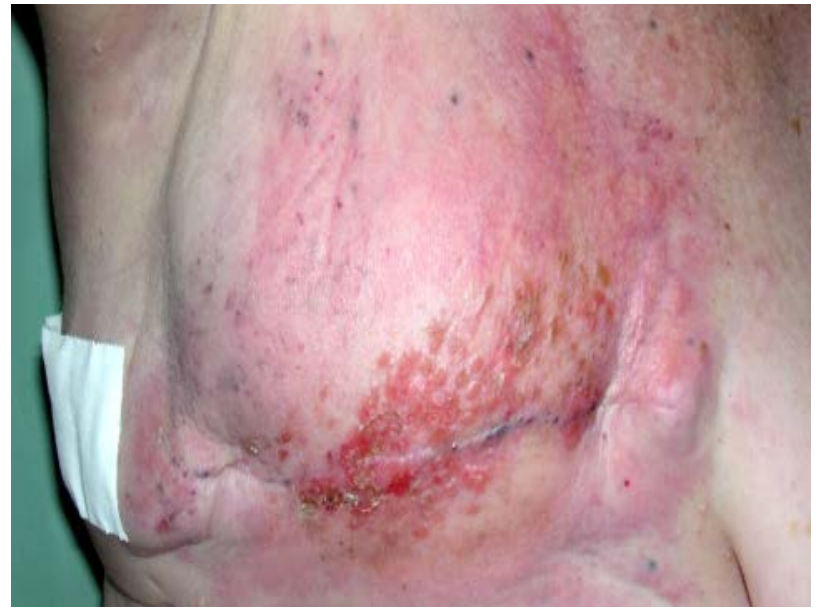

FIGURE 2. At the examination, infiltrated and hardened erythematous plaques of inaccurate limits were found, occupying the anterolateral region of the thorax and right breast

erage of $25 \%$ of cases. It may also arise from other tumor sites, such as the pancreas, stomach, colon, rectum, prostate, lung, ovary, and melanoma. ${ }^{2,3,5} \mathrm{Cu}-$ taneous metastases originating from breast cancer generally obey the principle of location according to a topographic region near the origin organ, so that the cutaneous metastasis that arises from breasts or lungs tend to be located in the thoracic area. Although the incidence of cutaneous metastases of all carcinomas is rare, it has been verified that it is mainly found among women with breast cancer. ${ }^{3,4,16}$

The present study patient presented, in her previous pathological history right, breast malignancy, namely ductal infiltrant carcinoma 3 years ago, when mastectomy and chemotherapy with Adriblastine and Genuxal were performed and combined with radiotherapy, which is in agreement with the literature. It is noteworthy that the original metastasis topography was maintained, since its site was at the right thoracic region and the intraductal infiltrant carcinoma was in the ipsilateral region of the tumor.

Erysipelatoid carcinoma is most commonly caused by mammary carcinoma but rarely associated with gastric adenocarcinoma, which shows that the present patient diagnosis is standard and truthful, once the epidemiology was maintained, because its site of origin was the ductal infiltrant carcinoma. ${ }^{17,25,26}$

In the present study, the patient presented in her disease history papuloerythematous, infiltrative-edematous, edematous cutaneous lesions with well-defined borders, slightly indurated, that resembled an acute infectious process, such as erysipelas and/or cellulitis. ${ }^{13,14,16}$ This clinical aspect is 


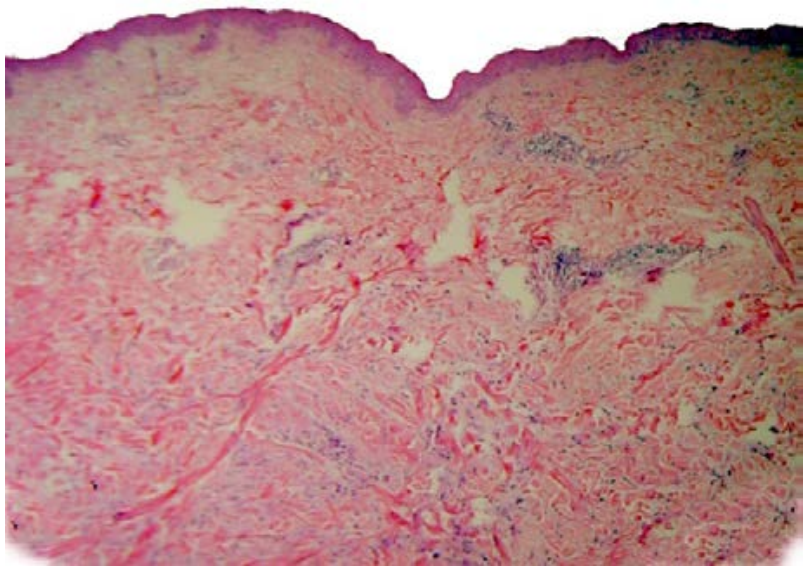

FIGURE 3. Photomicrograph showing fragments of skin infiltrated by adenocarcinoma with atypical neoplastic cells, forming cords and groups of tumor cells in the reticular dermis.

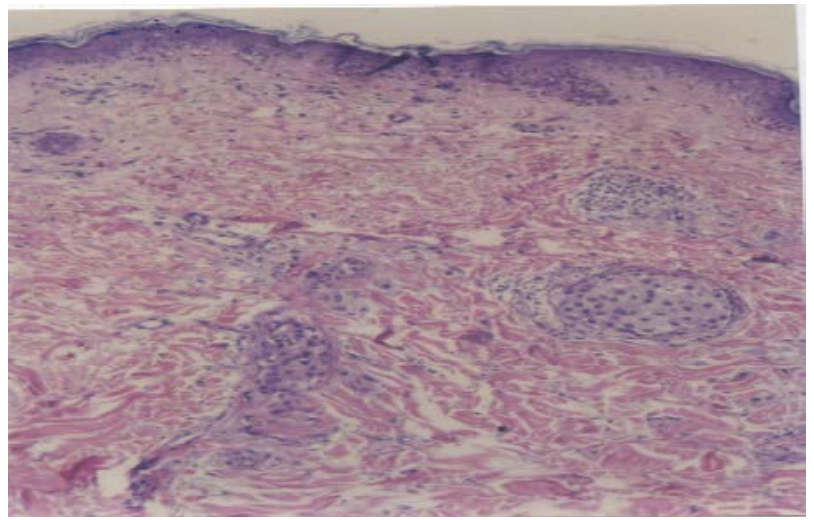

FIGURE 4. Photomicrograph showing fragments of skin infiltrated by adenocarcinoma with atypical neoplastic cells, forming cords and groups of tumor cells in the reticular dermis.

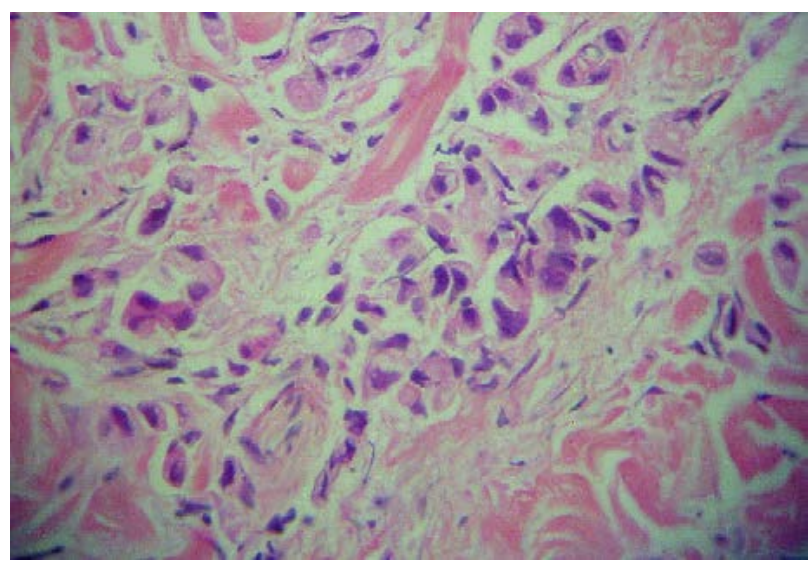

FIGURE 5. Presence of irregular aggregates of atypical epithelial cells forming cords and groups of cells that vary in size and shape infiltrated between collagen fibers in the reticular dermis.

characteristic of the pathology, since the literature describes this type of carcinoma as papular skin plaques with an erythematous aspect, infiltrated and with perilesional edema, well-demarcated and slight- ly indurated, so as to make a differential diagnosis from processes of infectious diseases such as cellulitis and erysipelas.

The skin lesion may persist for weeks or months, so that skin lesions often do not become apparent until some time has passed from the initial treatment of the original carcinoma. Its striking clinical aspect is difficult to diagnose and usually presents as a diagnostic challenge, since it can be easily confused with other clinical entities. It presents absence of fever or leukocytosis and negative bacterial culture, differentiating it from infectious processes such as erysipelas, cellulitis and mastitis., ${ }^{9,12,13}$ Other differential diagnoses include congestion, thrombophlebitis, post-surgical lymphedema, allergic reactions, post-radiotherapy dermatitis, herpes zoster infection, and hematoma. ${ }^{13,14}$

Complaining of an erythematous lesion and edema presence in the mastectomy region for 20 days, the patient denied fever and had previously been treated with Cephalexin, without improvement. In addition, to elucidate the situation, a complete hemogram was obtained, revealing: red blood cells: 4.12 / $\mathrm{mm}^{3}$, hemoglobin $11.9 \mathrm{mg} / \mathrm{dl}$, hematocrit $36.5 \%$, and a leukogram with 6400 leukocytes (0-3 / 0-0- 2-65 / 24-12), and biochemistry that did not present alterations. Initially, an infectious process was considered, but the clinical context and history did not fully support this diagnosis. In general, specific clinical features, such as a lack of feverish response, the absence of leukocytosis and prolonged presence of lesions from weeks to months, along with an absence of reaction to antibiotics, should alert to the possibility of cutaneous metastasis. Such laboratory results and lack of improvement with treatment confirm the pathology of non-bacterial pattern, despite its particular clinical aspect.

Metastatic cutaneous lesions usually occur in the final stage of cancer indicating that it may already have spread. Most patients have synchronous metastases in other organs., ${ }^{4,5,21}$ In the patient, however, only the breast was affected, and no other sites of metastatic implants were evident.

A cutaneous biopsy is usually necessary, revealing infiltration of tumor aggregates predominantly in dermal lymphatic vessels by neoplastic cells causing their obstruction. It should always be a differential diagnosis for the unilateral involvement of the thoracic wall erythematous aspect, which does not show improvement with antibiotic treatment and with an 


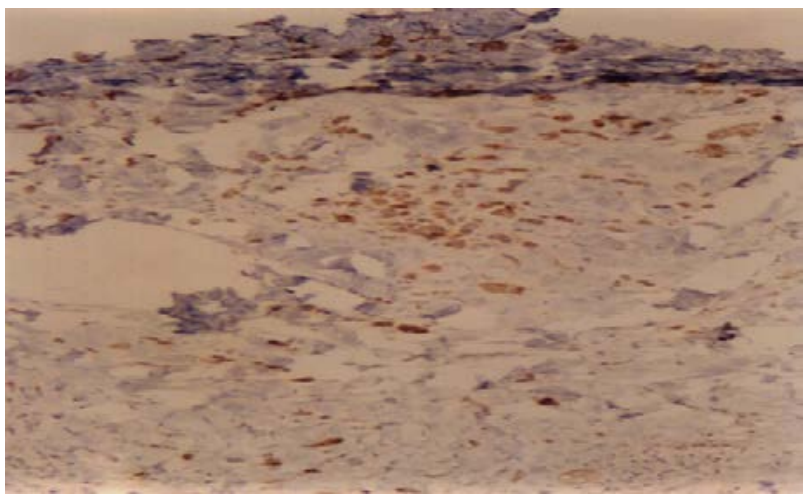

FIGURE 6. Ag BRST-2

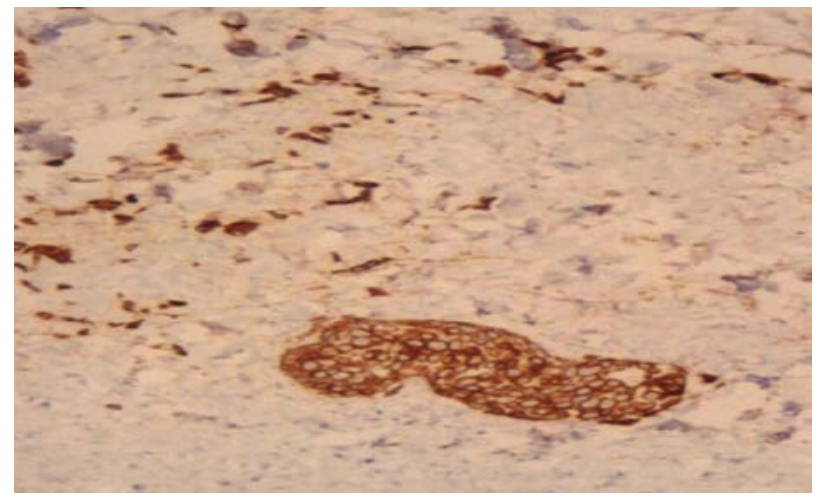

FIGURE 7. Citoqueratine 7 indurated appearance, mainly in patients with a previous history of malignancy. If the pathology is not correlated with the clinical findings, one should opt for deeper and repeated cutaneous biopsies if necessary. ${ }^{13-15}$ Metastatic cutaneous inflammatory carcinoma has more than one clinical morphology, but the skin cells metastasis have metastatic tumor cells in common, predominantly located in dermal vessels, either lymphatic or blood vessels, and which may be present in the dermis between collagen bundles. Immunoperoxidase containing antibodies that bind to specific antigens, mainly in the lymphatic and/or blood vessels, allows the identification of dermal vessels infiltrated by the tumor. ${ }^{4,5,18,19}$

Immunohistochemical techniques, such as cytokeratin 7 and cytokeratin 20, contribute to elucidate the diagnosis. BRST-2 antigen and estrogen and progesterone receptors may also be useful for diagnosis $^{9,15-17,27}$ The patient presented immunohistochemistry, with positive cytokeratin 7 , positive antigen BRST-2 (GCDFP-15), negative cytokeratin 20, negative estrogen receptor, evidencing and corroborating the disease pattern reflected by positive cytokeratin 7 and positive BRST- 2 antigen.

The rapid clinical appearance and aggressive nature of EC require immediate diagnosis and therapy to be started as early as possible to improve patient survival. ${ }^{13,17}$ Only with immediate recognition comes the opportunity to treat the systemic spread of cancer in the earlier stage as possible and improve survival rates. Thus, the response to induction chemotherapy is the most important prognostic factor. ${ }^{16,17,19}$ The prognosis varies depending on the primary cancer type but, most of the time, it presents a limited survival rate., ${ }^{5,11,28}$ That fact was decisive for beginning chemotherapeutic treatment in the patient.
EC treatment previously consisted only of surgery. Mastectomy is currently preferred by conservative breast surgery, but only produces an overall survival of months when used alone. Adjuvant radiotherapy has shown to improve locoregional tumor control but does not affect survival rates, and multimodality therapy is now the preferred option. ${ }^{13,21,27,29}$ Chemotherapy with Gemcitabine Hydrochloride and Paclitaxel was initiated in the patient, with partial edema regression and erythema after the $6^{\text {th }}$ chemotherapy session.

\section{CONCLUSION}

Cutaneous metastases are not common, but they are essential for signaling a possible primary cancer relapse or for alerting to possible occult neoplasia. Breast cancer one of the most common types of cancer that present skin metastasis and, when it does, it is usually to the chest wall. The dermatologic pattern of cutaneous metastases of breast cancer is that of solid, papulonodular lesions, but erysipeloid or armor infiltration is also possible.

After what was showed above, EC diagnosis should be considered in any persistent and therapeutically nonresponsive rash, like an infectious process, mainly in patients with previous malignant diseases.

Careful attention should be given to clinical features. Fever absence or leukocytosis such as persistence for a longer time, like weeks, contribute to a correct diagnosis of a noninfectious process.

Therefore, one should take a closer look at cutaneous lesions, especially those that affect patients with previous malignancies, so that diagnoses of less harmful malignancies are not considered as the first treatment option in patients with undiagnosed EC. 
PALAVRAS CHAVE: Neoplasias da mama. Erisipeloide. Neoplasias cutâneas. Inflamação/patologia.

\section{REFERENCES}

1. Nava G, Greer K, Patterson J, Lin KY. Metastatic cutaneous breast carcinoma: a case report and review of the literature. Can J Plast Surg. 2009;17(1):25-7.

2. French FP, Murray PM, Perdikis G. Extensive cutaneous metastatic breast carcinoma of the hand and upper extremity: a case report. J Hand Surg Am. 2007;32(2):252-5.

3. Azcune R, Spelta MG, Moya J, Jurjo ML, Fontana MI, Barbarulo AM, et al. etástasis cutáneas de carcinomas internos, nuestra experiencia a propósito de 94 casos. Dermatol Argent. 2009;15(2):117-24.

4. Vano-Galvan S, Moreno-Martin P, Salguero I, Jaen P. Cutaneous metastases of breast carcinoma: a case report. Cases ). 2009;2(1):71.

5. Hu SC, Chen GS, Lu YW, Wu CS, Lan CC. Cutaneous metastases from different internal malignancies: a clinical and prognostic appraisal. J Eur Acad Dermatol Venereol. 2008;22(6):735-40.

6. Uría MI, Chirino CN, Rivas DJ. Presentacion clínica inusual de metástasis cutánea de carcinoma mamario. A propósito de un caso. Rev Argent Dermatol.2009;90(4). [cited 2018 May 13]. Available from: http://www.scielo.org. $\mathrm{ar} /$ scielo.php?script=sci_arttext\&pid=S1851-300X2009000400006\&lng=es.

7. Fanale MA, Buzdar AU. Early-stage, locally advanced and inflammatory breast cancer. In: Kantarjian HM, Wolff RA, Koller CA, ed. Medical oncology. New York: McGraw-Hill; 2007.

8. Yamauchi H, Woodward WA, Valero V, Alvarez RH, Lucci A, Buchholz TA, et al. Inflammatory breast cancer: what we know and what we need to learn. Oncologist. 2012;17(7):891-9.

9. Canpolat F, Akpinar H, Eskioglu F, Genel N, Oktay M. A case of inflammatory breast carcinoma: carcinoma erysipeloides. Indian I Dermatol Venereol Leprol. 2010;76(2):215.

10. Jemal A, Bray F, Center MM, Ferlay J, Ward E, Forman D. Global cancer statistics. CA Cancer J Clin. 2011;61(2):69-90.

11. Ferlay |, Parkin DM, Steliarova-Foucher E. Estimates of cancer incidence and mortality in Europe in 2008. Eur J Cancer. 2010;46(4):765-81.

12. Toda-Brito H, Tavares E, Clemente E. Carcinoma erisipelóide. Acta Med Port 2015;28(2):268

13. Vega Gutiérrez, Rodríguez MA. Carcinoma erysipeloides associated with breast carcinoma. Int J Dermatol. 2007;46(6):613-4.

14. Eskevari S, Nejad KG. Carcinoma erysipeloid as the first manifestation of breast carcinoma: a case report. Iran J Dermatol. 2012;15:102-4.

15. Gugle A, Malpathak V, Zawar V, Deshmukh M, Kote R. Carcinoma erysipeloid: an unusual presentation that mimicking radiation dermatitis. Dermatol Online J. 2008;14(2):26.
16. Navaratnam AV, Chandrasekharan $S$. Remote cutaneous breast carcinoma metastasis mimicking dermatitis. Indian | Dermatol. 2015;60(1):106.

17. Nashan D, Müller ML, Braun-Falco M, Reichenberger S, Szeimies RM, Bruckner-Tuderman L. Cutaneous metastases of visceral tumors: a review. J Cancer Res Clin Oncol. 2009;135(1):1-14.

18. Acikalin MF, Vardareli E, Tel N, Saricam T, Urer S. Erysipelas-like cutaneous metastasis from gastric signet ring cell carcinoma. J Eur Acad Dermatol Venereol. 2005;19(5):642-3.

19. Godinez-Puig V, Frangos |, Hollmann TI, Dryden-Peterson S, Matulonis $U$, Lipworth AD. Rash in a patient with ovarian cancer. Clin Infect Dis. 2012;54(4):538, 575-6

20. Lee JH, Won CY, Kim EK, Jung JH, Kim GM, Kim SY. Carcinoma erysipeloides from adenocarcinoma of the lung. Ann Dermatol. 2013;25(3):373-5.

21. Yun SJ, Park HY, Leen JS, et al. Clinicopathological correlation of cutaneous metastatic breast carcinoma using lymphatic and vascular markers: lymphatics are mainly involved in cutaneous metastasis. Clin Exp Dermatol. 2012;37(7):744-8

22. Conner KB, Cohen PR. Cutaneous metastasis of breast carcinoma presenting as alopecia neoplastica. South Med J. 2009;102(4):385-9.

23. Kim JH, Kim MJ, Sim WY, Lew BL. Alopecia neoplastica due to gastric adenocarcinoma metastasis to the scalp, presenting as alopecia: a case report and literature review. Ann Dermatol. 2014;26(5):624-7.

24. Al Ameer A, Imran M, Kaliyadan F, Chopra R. Carcinoma erysipeloides as a presenting feature of breast carcinoma: a case report and a brief review of literature. Indian Dermatol Online J. 2015;6(6):396-8.

25. Kavgaci H, Reis A, Ozdemir F, Bektas O, Arslan M, Aydin F. Carcinoma erysipelatoides resulting from gastric adenocarcinoma: an unusual clinical presentation. Med Princ Pract. 2005;14(1):61-3.

26. Kunisaki C, Takahashi M, Nagahori Y, Fukushima T, Makino H, Takagawa $\mathrm{R}$, et al. Risk factors for lymph node metastasis in histologically poorly differentiated type early gastric cancer. Endoscopy. 2009;41(6):498-503.

27. Benevento R, Santoriello A, Perna G, Canonico S. Electrochemotherapy of cutaneous metastases from breast cancer in elderly patients: a preliminary report. BMC Surg. 2012;12(Suppl 1):S6.

28. Adelzadeh L, Breithaupt A, Jackson J, Worswick S. Purpuric plaque on the neck of a patient with breast carcinoma. Indian Dermatol Online ). 2014;5(3):348-9.

29. Dawood S, Merajver SD, Viens P, Vermeulen PB, Swain SM, Buchholz $\mathrm{TA}$, et al. International expert panel on inflammatory breast cancer: consensus statement for standardized diagnosis and treatment. Ann Oncol. 2011;22(3):515-23. 